\title{
A Comparison of Photocatalytic Oxidation Reactor Performance for Spacecraft Cabin Trace Contaminant Control Applications
}

\author{
Jay L. Perry ${ }^{1}$, Kenneth R. Frederick ${ }^{2}$, and Joseph P. Scott ${ }^{3}$ \\ National Aeronautics and Space Administration, Huntsville, Alabama, 35812, USA \\ and \\ Dana N. Reinemann ${ }^{4}$ \\ University of Mississippi, University, Mississippi, 38677, USA
}

\begin{abstract}
Photocatalytic oxidation (PCO) is a maturing process technology that shows potential for spacecraft life support system application. Incorporating PCO into a spacecraft cabin atmosphere revitalization system requires an understanding of basic performance, particularly with regard to partial oxidation product production. Four PCO reactor design concepts have been evaluated for their effectiveness for mineralizing key trace volatile organic compounds (VOC) typically observed in crewed spacecraft cabin atmospheres. Mineralization efficiency and selectivity for partial oxidation products are compared for the reactor design concepts. The role of PCO in a spacecraft's life support system architecture is discussed.
\end{abstract}

\section{Nomenclature}

$C \quad=$ Celsius

$\mathrm{cm} \quad=$ centimeter

hr $\quad=$ hour

$m \quad$ = meter

$m g \quad=$ milligram

$\mathrm{nm} \quad=$ nanometer

\section{Introduction}

DhOtocatalytiC oxidation is emerging as a process technology of interest to enable long duration, crewed space exploration missions. As mission objectives reach beyond the lunar-Earth system specific functional capabilities become increasingly important for the environmental control and life support (ECLS) system. These capabilities include highly efficient resource recovery and minimal overboard venting. The overall ECLS system must strive to fit within a small mass and volume package, require minimal electrical power, and have minimal logistical support needs. By definition the ECLS system must be highly efficient and reliable.

Experience gained by operating the ECLS systems on board the International Space Station (ISS) provides insight on various areas for improving the design and function. One area for improvement involves reducing water processing assembly (WPA) life cycle costs and logistics support needs by minimizing volatile organic compound (VOC) mass transfer into humidity condensate. The potential sensitivity of WPA process economics to the VOC loading in humidity condensate was established in 2002. ${ }^{1}$ Flight operations protocols were later established to limit the total airborne polar VOC concentration to $<5 \mathrm{mg} / \mathrm{m}^{3}$. Given that polar VOCs-primarily ethanol, 2-propanol, and 2-propanone - are used for cleaning equipment before transport to the ISS as well as their use as ingredients in a

\footnotetext{
${ }^{1}$ Engineer, Environmental Control Systems, NASA Marshall Space Flight Center, Huntsville, AL 35812.

${ }^{2}$ Electronics Engineer, NASA Marshall Space Flight Center, Huntsville AL 35812.

${ }^{3}$ Chemist, ICRC/Jacobs/ESTS, NASA Marshall Space Flight Center, Huntsville, AL 35812.

${ }^{4}$ Student, University of Mississippi, School of Engineering, Dept. of Chemical Engineering/College of Liberal Arts, Dept. of Chemistry and Biochemistry, University, Mississippi, 38677.
} 
wide range of personal care and housekeeping products used on board the ISS, meeting the $<5 \mathrm{mg} / \mathrm{m}^{3}$ target concentration has proved to be challenging as shown by the concentration profile shown in Fig. 1. This challenge persists despite efforts to limit polar VOC use on board the ISS.

Traditionally-designed trace contaminant control (TCC) equipment operates at flow rates $<25 \mathrm{~m}^{3} /$ hour and processes air in parallel with humidity control equipment. ${ }^{2,3}$ This arrangement allows polar VOCs to come into contact with and partition into humidity condensate. This polar VOC load presents a challenge for managing WPA expendable components and system life cycle costs. To address this challenge, a change in TCC equipment design and loca-

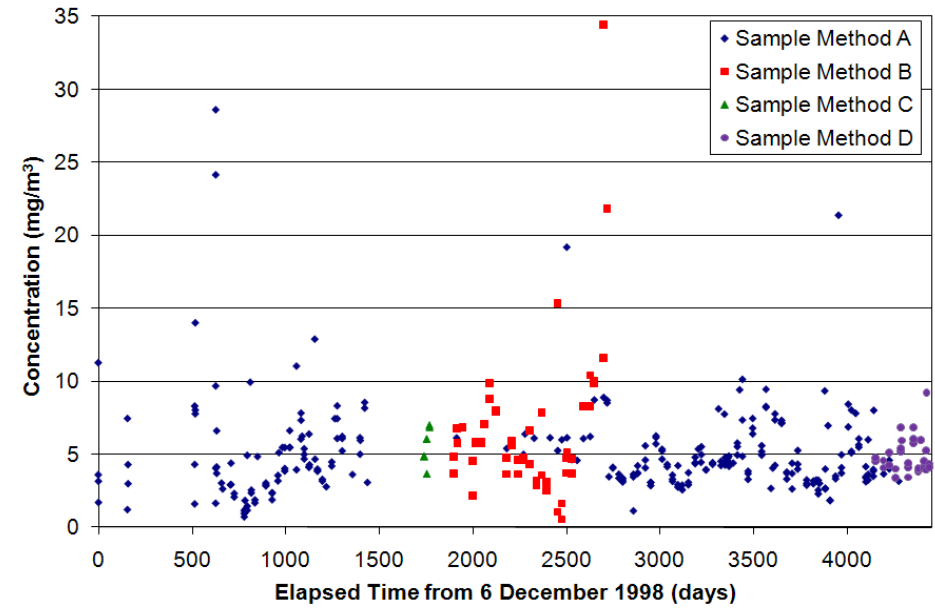

Figure 1. Polar VOC concentration aboard ISS. tion has been proposed. ${ }^{4}$ This proposed concept locates the TCC equipment in a primary cabin ventilation duct upstream of the humidity control equipment. The objective is to reduce the polar VOC concentration entering the humidity control process equipment by $>80 \%$ to, in turn, reduce the WPA's processing load and improve overall process life cycle economics.

Photocatalytic oxidation (PCO) is a leading candidate to provide the needed high volumetric flow TCC function in a power-efficient, compact package. Several commercial PCO-based products designed to be installed in heating, ventilation, and air conditioning (HVAC) ducts are available. These commercial PCO products are typically marketed more for their biocidal function rather than for VOC control and use a titania $\left(\mathrm{TiO}_{2}\right)$ photocatalyst applied to various substrates. Photocatalyst illumination is typically accomplished with mercury- (Hg-) vapor lamps. The National Aeronautics and Space Administration (NASA) has sponsored projects at universities and aerospace companies to develop PCO into a viable TCC process technology. ${ }^{5-8}$ An experimental ECLS system architecture employing PCO was evaluated in 2007. ${ }^{9}$ This investigation reported reasonable performance from an unmodified, commercially available PCO unit mounted in the main ventilation duct; however, some partial oxidation product generation contributed to an undesirable increase in acetate loading of the humidity condensate to be fed to the WPA equipment. This observation is not surprising given some of the technical challenges associated with PCO. These technical challenges include hazards associated with using $\mathrm{Hg}$-vapor lamps for catalyst illumination, traditionally low single pass oxidation efficiency that requires multiple processing passes for VOC control, partial oxidation product generation, and catalyst activity degradation.

A follow-up effort was undertaken by NASA to evaluate two commercially-available and two custom-developed PCO units for VOC oxidation performance. Results from this evaluation are presented in the following discussion.

\section{Background}

In a photocatalytic process, photons of sufficient energy are absorbed by a semiconductor (SC) substrate - the photocatalyst. When the energy is sufficient to overcome the activation barrier, or band gap (Bg), between the valence and conduction bands, excited electron states result. Electrons are promoted from the valence band (VB) to the conduction band (CB), leaving positively-charged holes $\left(h^{+}\right)$behind in the VB and electrons $(e)$ in the $\mathrm{CB}$, as seen in Eq. $1 .{ }^{10}$ Ultraviolet (UV or $h v$ ) light wavelengths ranging between $185 \mathrm{~nm}$ and $400 \mathrm{~nm}$ possesses the necessary energy to initiate photocatalysis. Lamps producing UV wavelengths of $254 \mathrm{~nm}$ and $365 \mathrm{~nm}$ are commonly used.

$$
S C \stackrel{h v>B g}{\rightarrow} e_{C B}^{-}+h_{V B}^{+}
$$

Because opposite charges attract, the process of Eq. 1 would be counterproductive if there was not anything else in the system to stop the recombination of the electrons and holes. This is where the oxidation and reduction reactions play a role. In the presence of sufficient oxygen, the oxygen attacks the free electron radicals in the CB producing superoxide ions $\left(\mathrm{O}_{2}{ }^{-}\right)$shown in Eq. 2. The positively-charged holes then react with water molecules that are present, forming hydroxyl radicals $(\mathrm{OH} \bullet)$, Eq. 3, and commencing radical propagation between $\mathrm{OH} \bullet$ and perhydroxyl radicals $\left(\mathrm{HO}_{2}{ }^{\bullet}\right)$ that are formed from $\mathrm{O}_{2}{ }^{-}$and $h^{+}$, also shown in Eq. 4. Hydrogen peroxide $\left(\mathrm{H}_{2} \mathrm{O}_{2}\right)$ is also formed from $\mathrm{HO}_{2} \bullet$ and $h^{+}$, Eq. 5, and it is then split by $h v$ to produce more $\mathrm{OH} \bullet$, Eq. $6 .{ }^{11}$ 


$$
\begin{gathered}
\mathrm{O}_{2}+e^{-} \rightarrow \mathrm{O}_{2}^{-} \\
h^{+}+\mathrm{H}_{2} \mathrm{O} \rightarrow \mathrm{OH} \bullet+h^{+} \\
\mathrm{O}_{2}^{-}+h^{+} \rightarrow \mathrm{HO}_{2} \bullet \\
\mathrm{HO}_{2} \bullet+h^{+}+e^{-} \rightarrow \mathrm{H}_{2} \mathrm{O}_{2} \\
\mathrm{H}_{2} \mathrm{O}_{2} \rightarrow 2 \mathrm{OH} \bullet
\end{gathered}
$$

Hydroxyl radicals, some of the strongest oxidizing agents, are capable of partially cleaving carbon-carbon double bonds to form unstable single bond intermediates. These intermediates then react further to $\mathrm{CO}_{2}$ and $\mathrm{H}_{2} \mathrm{O}$ products to terminate the reaction chain as shown by Eq. 7. Figure 2 illustrates the concept of photocatalytic oxidation. ${ }^{12}$

$$
\mathrm{VOCs}+\mathrm{OH} \bullet \rightarrow \mathrm{CO}_{2}+\mathrm{H}_{2} \mathrm{O}
$$

\section{Photocatalytic Oxidation Test Articles}

Four PCO configurations were evaluated. Two commercially available PCO units designed for installation into HVAC ducts were acquired. The commercial units are designed to accommodate typical HVAC flow rates. These PCO units were not modified and installed "as is" directly into a test chamber's ventilation system. The commercial PCO units were exposed to $\sim 680 \mathrm{~m}^{3} /$ hour or approximately 5 times less flow than for a typical residential HVAC system application. Two custom-designed PCO units were acquired. These custom PCO units were designed to accommodate up to $\sim 85 \mathrm{~m}^{3} /$ hour flow. Each PCO unit configuration is briefly described.

\section{A. Commercial PCO Unit A}

The first commercially available PCO unit employed a photocatalyst applied to an approximately $0.08-\mathrm{cm}$ thick non-metallic, pleated mesh substrate. Each $5.1-\mathrm{cm}$ deep pleated mesh catalyst panel was approximately 91.4 $\mathrm{cm}$ long $\times 48.3 \mathrm{~cm}$ high. Approximately 0.86 pleats $/ \mathrm{cm}$ increased the catalyst media length dimension by approximately a factor of eight. A single PCO unit has two sets of photocatalyst panels oriented in a chevron pattern rela-

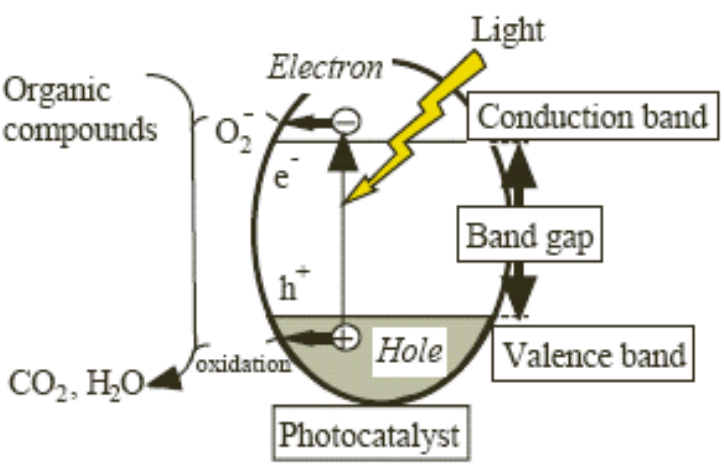

Figure 2. Photocatalytic Oxidation Reaction. ${ }^{12}$ Conceptual image of the processes involved in the reaction of photocatalysts with UV light, which has enough energy to promote an electron from the $V B$ to the CB. Oxygen species take over the electron while water is oxidized from the $h^{+}$. Radical propagation between hydroxyl radicals takes place until $\mathrm{CO}_{2}$ and $\mathrm{H}_{2} \mathrm{O}$ formation terminates the reaction. tive to the air flow. Two PCO units were installed in series. The closed end of the chevron faced into the air flow. Two mercury vapor lamps are placed on the inside of the open end of each chevron and on the outside of the closed end of each chevron. A total of 6 lamps illuminated each set of photocatalyst panels. The lamps are oriented parallel to the air flow. The unit's inlet is protected using a high efficiency particulate filter. Each set of catalyst panels and lamps was housed in a sheet metal duct measuring 50.8 $\mathrm{cm}$ wide $\times 50.8 \mathrm{~cm}$ high $\times 114.3 \mathrm{~cm}$ long. The total length was $228.6 \mathrm{~cm}$ for the two sets of catalyst panels and lamps. The cross sectional area for flow affords $73.1 \mathrm{~cm} / \mathrm{second}$ flow velocity at the testing conditions. Residence time in the configuration testing was approximately 3.1 seconds. The estimated catalyst contact time was approximately 0.059 seconds.

\section{B. Commercial PCO Unit B}

The second commercially available PCO unit employed a photocatalyst applied to a $2.54-\mathrm{cm}$ thick ceramic honeycomb substrate. The honeycomb substrate channels are oriented parallel to the air flow. Two Hg-vapor lamps are located upstream of the honeycomb catalyst panel. These lamps are oriented perpendicular to the catalyst panel and air flow. The unit's inlet is protected by a high efficiency particulate filter. The PCO unit's dimensions are $49.5 \mathrm{~cm}$ wide $\times 62.2 \mathrm{~cm}$ high $\times 25.4 \mathrm{~cm}$ long. The available cross sectional area for flow provides $61.2 \mathrm{~cm} / \mathrm{second}$ flow velocity at the testing conditions. Two PCO units were arranged in series to provide a total residence time of 0.82 seconds. The catalyst contact time was approximately 0.083 seconds. 


\section{Developmental PCO Unit A}

The first developmental PCO unit employed a doped $\mathrm{TiO}_{2}$ photocatalyst applied to $\sim 0.13$-cm thick metallic mesh panels. A series of 6 mesh panels were oriented perpendicular to the air flow to provide $\sim 0.73 \mathrm{~cm}$ total catalyst thickness. Mercury vapor lamps were located between each bank of mesh panels. A total of 24 lamps were used to illuminate the catalyst. The PCO unit's dimensions of $63.5 \mathrm{~cm}$ wide $\times 50.8 \mathrm{~cm}$ high $\times 35.6 \mathrm{~cm}$ long provided 7.3 $\mathrm{cm} /$ second flow velocity at the testing conditions. The PCO unit's dimensions provided a 4.9-second total residence time. Catalyst contact time was approximately 0.1 seconds.

\section{Developmental PCO Unit B}

The second developmental PCO unit employed a $\mathrm{TiO}_{2}$ photocatalyst deposited on a pelletized silica-based adsorbent media. The pelletized photocatalyst media was retained in a packed bed. Thirteen quartz tubes oriented perpendicular to the air flow inside the bed volume allowed for Hg-vapor lamps to be inserted inside the packed bed of photocatalyst. The lamps were arranged in a staggered pattern to maximize photocatalyst illumination. The photocatalyst packed bed dimensions of approximately $17.8 \mathrm{~cm}$ wide $\times 27.9 \mathrm{~cm}$ high $\times 30.5$ inches deep provided 47.9 $\mathrm{cm} /$ second flow velocity at the testing conditions. The packed bed dimensions minus the volume occupied by the quartz tubes provided a 0.56 -second residence time. Accounting for packed bed void fraction, the catalyst contact time was approximately 0.2 seconds.

\section{Evaluation Approach}

\section{A. Test Chamber Characteristics}

Each candidate PCO unit was installed in a sealed chamber for evaluation. The chamber, shown in Fig. 3 and known as the Regenerative Environmental Control and Life Support System (ECLSS) Module Simulator (REMS), is located at NASA's Marshall Space Flight Center (MSFC). The REMS chamber volume is $\sim 201 \mathrm{~m}^{3}$ and is equipped with a ventilation system containing a condensing heat exchanger and blower package as well as temperature control, humidity injection, and VOC injection and monitoring capabilities. Various atmospheric parameters were controlled and monitored. The nominal ambient testing conditions in the REMS for VOC removal with the PCO reactor is to maintain the relative humidity above $30 \%$ and the temperature between $21.1^{\circ} \mathrm{C}$ and $26.7^{\circ} \mathrm{C}$. Chamber pressure was maintained at approximately the local barometric pressure.

\section{B. Photocatalytic Oxidation Test Article Installation}

Two installation approaches were used depending on the PCO unit design. One installation approach was used for the commercial PCO units and the second approach was used for the developmental PCO units. Details on each installation are discussed briefly.

\section{Commercial PCO Unit Installation}

Each commercial PCO unit was installed directly into the REMS chamber main ventilation supply duct located under the floor. A metallic mesh particulate filter was installed at the PCO unit inlet. The PCO unit was installed upstream of the cabin fan and condensing heat exchanger package. Chamber air flow was drawn by the cabin fan

2. Developmental PCO Unit Installation

Each developmental PCO unit was installed in the mid-chamber aisle way shown in Fig. 3. A calibrated venturi flow meter was located downstream of the developmental PCO unit under evaluation. A variable speed fan pulled the process air from the REMS working volume through the PCO unit and flow meter. The exhaust from the PCO test rig was directed into the chamber's ventilation system supply inlet using a flexible duct.

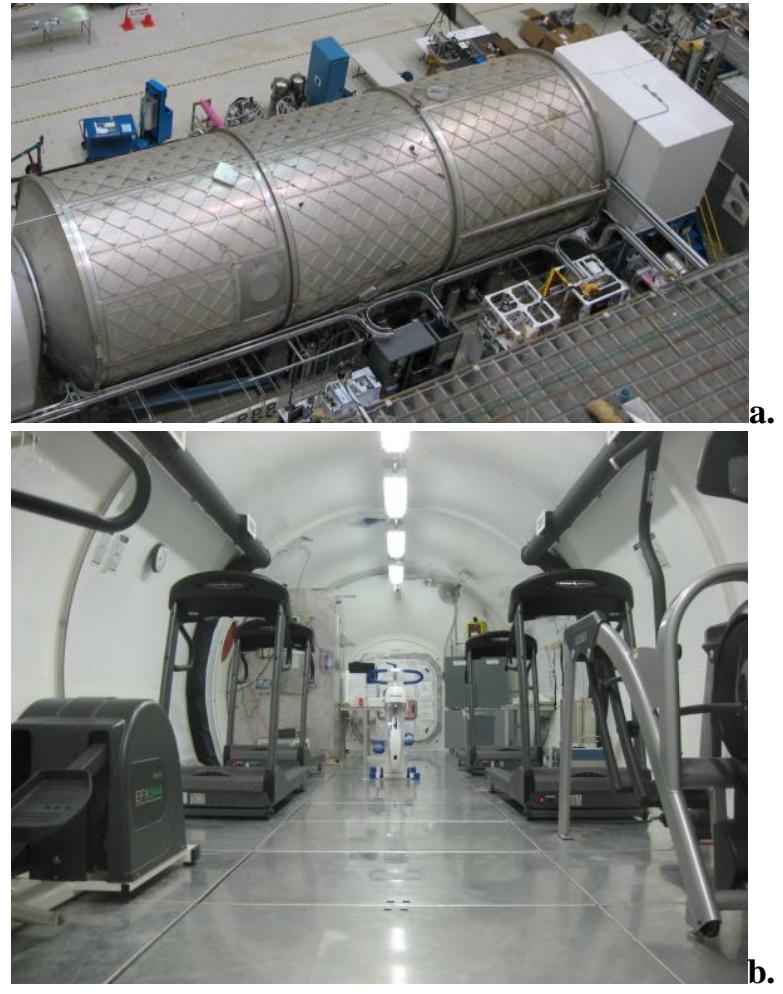

Figure 3. Regenerative ECLSS Module Simulator chamber. a) exterior view, b) interior view. 


\section{Volatile Organic Compound Injection and Analytical Methods}

Chemical challenges are introduced into the REMS by injecting a prepared liquid VOC solution into a heated duct maintained between $100{ }^{\circ} \mathrm{C}$ and $108.9^{\circ} \mathrm{C}$ to facilitate its evaporation. Injection was accomplished by a computer controlled syringe pump. An air stream drawn from the REMS ventilation system sweeps the vaporized VOCs into the chamber's working volume via the ventilation system. The injection point is located downstream of the REMS condensing heat exchanger in one of the two ventilation return ducts. Liquid VOC solutions used for each chemical challenge run are summarized in Table 1. Ethanol is common to all the injection mixtures because it is of most interest.

Two chemical challenge injection techniques were employed. For the commercial PCO units, the VOC injection was initiated at the same time that the PCO units were powered. The VOC concentration was monitored over time and the dynamic profile was evaluated to extract performance results. For the developmental PCO units, an initial chemical charge was introduced to produce a starting contaminant concentration inside the REMS. The initial injection spike was designed to reach $\sim 9 \mathrm{ppm}$ ethanol in the chamber working volume. After the initial injection, the ethanol concentration was allowed to stabilize between $3 \mathrm{ppm}$ and $5 \mathrm{ppm}$. Once the concentration equilibrated, the PCO unit under evaluation was powered.

Table 1. PCO unit chemical challenges.

\begin{tabular}{|l|c|c|c|c|c|c|}
\hline \multirow{3}{*}{ Contaminant } & \multirow{2}{*}{$\begin{array}{c}\text { Injection } \\
\text { Rate } \\
\text { (mg/hr) }\end{array}$} & \multicolumn{5}{|c|}{ Challenge Mixture } \\
\hline & & $\mathbf{1}$ & $\mathbf{2}$ & $\mathbf{3}$ & $\mathbf{4}$ & $\mathbf{5}$ \\
\hline \hline Ethanol & 135 & $\checkmark$ & $\checkmark$ & $\checkmark$ & $\checkmark$ & $\checkmark$ \\
\hline m-Xylene & 2 & & $\checkmark$ & & & $\checkmark$ \\
\hline Dichloromethane & 1.2 & & & $\checkmark$ & & $\checkmark$ \\
\hline Acetone & 3.5 & & & & $\checkmark$ & $\checkmark$ \\
\hline Acetaldehyde & 3.2 & & & & & $\checkmark$ \\
\hline Methanol & 6.6 & & & & & $\checkmark$ \\
\hline 2-Propanol & 5.1 & & & & & $\checkmark$ \\
\hline Propylene glycol & 38.2 & & & & & $\checkmark$ \\
\hline Benzyl alcohol & 5.1 & & & & & $\checkmark$ \\
\hline
\end{tabular}

\section{Analytical Methods}

During each chemical mixture challenge run, a pump pulled gas samples from the chamber working volume into sample distribution lines that supplied two analytical instruments. The first instrument was an MKS Multigas ${ }^{\mathrm{TM}}$ 2030 Fourier Transform Infrared Spectrometer (FTIR) while the second was an Agilent 6890N gas chromatograph (GC). Atmospheric samples were collected from two locations - the inlet and outlet of the PCO reactor test article under evaluation. Samples were analyzed from the PCO reactor inlet until the ethanol concentration reported by the FTIR instrument reached a plateau indicating a near steady state. At that time, samples were collected from the PCO reactor outlet before switching back to the PCO reactor inlet. Ethanol was used not only as a chemical challenge for the PCO reactor evaluations but also served as the target compound to control the chemical injection system.

The MKS Multigas ${ }^{\mathrm{TM}} 2030$ FTIR collects infrared spectral absorption data to monitor the levels of certain gases. Ethanol was the primary target compound for FTIR analysis not only for evaluating PCO reactor performance but also to assist in chemical injection system control and to provide insight on atmospheric parameters in the chamber working volume that are necessary to ensure safe test operations. In addition to monitoring ethanol, the FTIR instrument also provided near real-time monitoring for oxygen $\left(\mathrm{O}_{2}\right)$, carbon monoxide $(\mathrm{CO})$, carbon dioxide $\left(\mathrm{CO}_{2}\right)$, and water $\left(\mathrm{H}_{2} \mathrm{O}\right)$ levels. The FTIR analysis rate was 1 scan every 2-3 seconds.

The Agilent $6890 \mathrm{~N}$ GC was equipped with a flame ionization detector (FID) to analyze all the chemical challenge compounds listed in Table 1. The sample gases were pulled into a Markes TT24/7 autosampler for a specified amount of time and flow rate. The autosampler uses two sub-ambient temperature traps to capture the targeted chemical analytes. A temperature ramp is used to desorb the trapped chemical analytes into the GC. A sample is introduced to one trap while the other trap is being desorbed into the GC. The GC uses a glass capillary column and a controlled temperature ramp to separate the gases based on their molecular weight and retention time on the column. Results were reported from GC analysis at approximately 30-minute intervals. This interval was dictated by autosampler trap cycling. Each GC run required approximately 18 minutes.

The FTIR and GC analytical instruments worked very well for detecting and quantifying the resulting concentrations for each chemical challenge mixture injected into the chamber working volume. Not only did the technique work analytically to support the different mixes of gases being evaluated, but it was also provided excellent safety monitoring for testing personnel. 


\section{Results}

Results obtained from challenging four PCO units with the challenge mixtures listed in Table 1 were compiled and evaluated for ethanol single pass removal efficiency, acetaldehyde outlet-to-inlet ratio, and VOC single pass removal efficiency. Specific observations pertaining to these areas are presented by the following summary.

\section{A. Ethanol Single Pass Efficiency}

Reducing the prevailing ethanol concentration at the PCO unit inlet is a key performance parameter for the targeted application. Performance of the four PCO units as a function of estimated catalyst contact time is presented by Fig. 4. Not surprisingly the single pass ethanol removal efficiency correlates to the estimated catalyst contact time with the shorter contact times performing less effectively compared to the longer contact times. Both commercial PCO units employed the lower contact times. Developmental PCO unit A employed a contact time not much greater than the commercial PCO units. The improved performance at the approximately 0.1 -second contact time indicates that the doped $\mathrm{TiO}_{2}$ catalyst applied to a metallic mesh likely possesses significantly greater activity compared to the catalyst used in the commercial PCO units. The performance improvement over the commercial PCO units is dramatic, averaging $~ 700 \%$. Developmental PCO unit B, which uses a UV-transparent adsorbent to support the photocatalyst, shows the potential for $>20 \%$ improvement compared to developmental PCO unit A, which uses a photocatalyst alone.

Ethanol removal by developmental PCO unit B was observed to decline in the presence of some compounds. Figure 5 shows the concentration reduction performance for several chemical challenge runs. The run containing ethanol and m-xylene showed potentially decreased activity compared to the runs for ethanol alone and ethanol in combination with acetone. The performance for ethanol concentration reduction was also reduced for the multicomponent challenge run but not to the extent observed during the run containing

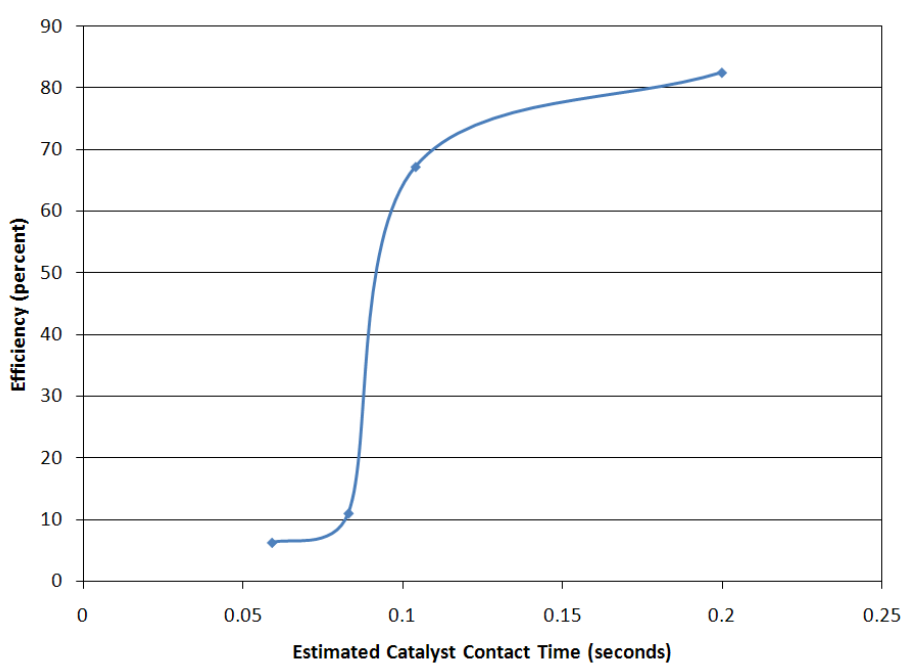

Figure 4. Ethanol single pass removal efficiency. Developmental PCO units perform significantly better than commercial PCO units.

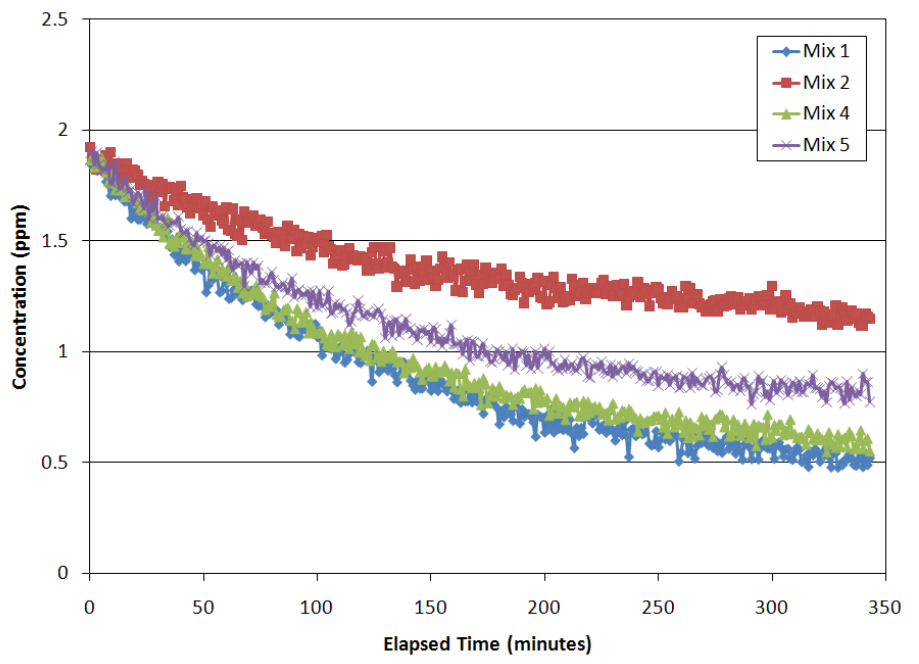

Figure 5. Ethanol concentration reduction by developmental PCO unit B. Trends show possible co-adsorption effects from $\mathrm{m}$ xylene and a mixture of VOCs. Acetone does not appear to affect performance. ethanol in combination with $\mathrm{m}$-xylene. This observation indicates that it may be necessary to consider coadsorption effects when designing a PCO unit that employs combined physical adsorption and photocatalytic processes.

\section{B. Acetaldehyde Outlet-to-Inlet Ratio}

Developmental PCO unit A produced the least acetaldehyde. Across all chemical challenge runs this PCO unit showed an acetaldehyde concentration outlet-to-inlet ratio of 0.50. Developmental PCO unit B performed similarly with an outlet-to-inlet ration of 0.56 . Both commercial PCO units performed poorly by comparison. Commercial 
PCO unit A averaged an acetaldehyde outlet-to-inlet ratio of 0.89 while commercial PCO unit B averaged 0.95. During catalyst formulation for developmental PCO unit A, it was noted that acetaldehyde production was possible when the catalyst is not illuminated. The unit's design does result in no illumination of one side of both the inlet and outlet catalyst panels. Therefore it is very likely that performance can be improved.

\section{Volatile Organic Compound Removal Efficiency}

All of the PCO units evaluated removed VOCs other than ethanol to a varying degree. Table 2 summarizes the average single pass removal efficiency for each PCO unit. Overall, compounds in the alcohol and ketone functional classes are handled by all of the PCO units. As in other areas, the developmental PCO units exhibited much better performance with developmental unit B clearly performing best. Dichloromethane and benzyl alcohol appear to be particularly challenging for all the PCO units. With the exception of developmental PCO unit A, no significant dichloromethane removal was observed. No removal of benzyl alcohol was observed for any PCO unit. Commercial PCO unit B removed propylene glycol and m-xylene reasonably well; however, both develop-

Table 2. Volatile organic compound removal efficiency summary.

\begin{tabular}{|l|c|c|c|c|}
\hline \multirow{2}{*}{ COMPOUND } & \multicolumn{4}{|c|}{ SINGLE PASS EFFICIENCY (\%) } \\
\cline { 2 - 5 } & \multicolumn{2}{|c|}{ Commercial Unit } & \multicolumn{2}{c|}{ Developmental Unit } \\
\cline { 2 - 5 } & A & B & A & B \\
\hline Methanol & 11.7 & 0 & 29 & $>50$ \\
\hline 2-propanol & 9 & 19.4 & 10 & 88 \\
\hline 2-propanone & 13.4 & 6 & 27 & 47 \\
\hline Dichloromethane & 0 & 0.5 & 9 & 0 \\
\hline Propylene glycol & 0 & 20 & 36 & 79 \\
\hline m-xylene & 0 & 20 & 38 & $>50$ \\
\hline Benzyl alcohol & 0 & 0 & 0 & 0 \\
\hline
\end{tabular}

mental units demonstrated substantially improved removal performance for these compounds. In all, developmental PCO unit B averaged $62.8 \%$ removal efficiency for five compounds while developmental PCO unit A averaged $24.8 \%$ removal efficiency for six compounds. Both commercial units averaged between $11 \%$ and $13 \%$ for those compounds that indicated removal activity.

\section{Discussion}

Evaluation of four PCO units for potential application to spacecraft TCC has found that PCO has potential. The commercial PCO units and developmental unit A have demonstrated that a low pressure drop TCC process is possible. With careful catalyst formulation, as demonstrated by both developmental PCO units, the single pass removal efficiency target for ethanol can be reached and selectivity for acetaldehyde production can be reduced by nearly $50 \%$ compared to commercially available units. In spite of these performance gains, significant developmental work remains. This work must address several technical areas.

\section{A. Catalyst Development for Reduced Partial Oxidation Product Selectivity}

The developmental testing undertaken demonstrated that partial oxidation product selectivity must be improved for PCO processes. While the developmental PCO units exhibited marked improvement compared to the commercial PCO units, using PCO in a spacecraft cabin with no effluent processing is not possible. Not only was acetaldehyde confirmed analytically during the testing runs but testing personnel reported a vinegar-like odor at the conclusion of some runs. The odor can be attributed to acetic acid production. Acetic acid has a recognition odor threshold as low as $1 \mathrm{ppm} .{ }^{13}$ This should be no surprise since acetic acid is reported as a partial oxidation product in a PCO evaluation conducted by Hodgden et al in 2005. ${ }^{14}$ Future PCO developmental efforts for spacecraft cabin applications must emphasize reducing aldehyde and organic acid product selectivity.

\section{B. Pressure Drop Management}

Low pressure drop characteristics are implicit to applying PCO to high volumetric flow conditions to reduce polar VOC absorption into humidity condensate. The PCO unit designs that employed thin photocatalyst substrates address the need for minimal pressure drop. The developmental PCO unit B that employed a photocatalyst supported on adsorbent pellets required a significantly more powerful fan to provide the necessary volumetric flow. While exhibiting very good VOC removal performance, this unit is limited by its pressure drop characteristics. The developmental PCO unit A possessed the best overall combination of pressure drop and VOC removal performance. Fu- 
ture work should address the most energy efficient PCO configuration for combined pressure drop management and VOC removal performance.

\section{Safe Catalyst Illumination Technology}

All of the PCO units evaluated illuminated the photocatalyst with Hg-vapor lamps. In a spacecraft cabin, $\mathrm{Hg}$ vapor lamp structural failure presents a significant cabin air quality hazard that must be controlled. Usually this means that Hg-vapor lamp housings must provide multiple containment levels relative to the cabin atmosphere to prevent $\mathrm{Hg}$ introduction into the cabin if a lamp breaks. Work on alternative illumination techniques, particularly UV light-emitting diodes (LED) is of particular interest to address this hazard.

\section{Photocatalyst Durability}

Photocatalyst activity loss over time is a significant concern. Testing conducted in 2007 using commercial PCO unit A showed $>50 \%$ single pass efficiency degradation for all compounds monitored. ${ }^{15}$ Further, Hay et al reports that photocatalysts can be deactivated by airborne siloxanes. ${ }^{16}$ This is a challenge for PCO application on board spacecraft because siloxanes typically account for a significant portion of the spacecraft cabin offgassing load and therefore the total trace chemical contaminant composition of the cabin atmosphere. ${ }^{17,18}$

\section{Summary}

Four PCO units were evaluated for their potential application to high volumetric flow rate trace contaminant control challenges in crewed spacecraft. Two commercial PCO units exhibited low ethanol removal performance and high potential for acetaldehyde production. Two developmental PCO units exhibited greatly improved performance with respect to ethanol and VOC removal as well as $42 \%$ lower acetaldehyde production.

Developmental challenges exist for PCO processes. These challenges include pressure drop management, susceptibility to poisoning from compounds such as siloxanes, implementing safe lamp technologies, and partial oxidation product production. PCO processes that employ a physical adsorption component may be limited to low volumetric flow applications due to pressure drop challenges presented by packed beds.

\section{Conclusion}

Evaluation of four PCO units for trace contaminant control applications indicates good potential for the targeted application. Improving PCO catalyst activity and reducing susceptibility to poisoning are essential to applying the technology broadly to spacecraft TCC challenges. Developing reactor designs and catalyst formulations that eliminate partial oxidation product production is imperative for PCO applications in sealed habitable volumes such as a spacecraft cabin. Developing safe, $\mathrm{Hg}$-free catalyst illumination components is also an important developmental area for enabling PCO applications in spacecraft cabins.

\section{Acknowledgments}

The authors with to thank the NASA Academy at Marshall Space Flight Center, the NASA Innovative Partnership Program, and the NASA Exploration Technology Development Program for sponsoring parts of this work.

\section{References}

${ }^{1}$ Perry, J. L., "The Interaction of Spacecraft Cabin Atmospheric Quality and Water Processing System Performance,” 200201-2300, SAE, 32 ${ }^{\text {nd }}$ International Conference on Environmental Systems, San Antonio, Texas, 2002.

${ }^{2}$ Perry, J. L., Curtis, R. E., Alexandre, K. L., Ruggiero, L. L., and Shtessel, N., "Performance Testing of a Trace Contaminant Control Subassembly for the International Space Station," 981621, SAE, $28^{\text {th }}$ International Conference on Environmental Systems, Danvers, Massachussetts, 1998.

${ }^{3}$ Curtis, R. E., Perry, J. L., and Abramov, L. H., "Performance Testing of a Russian Mir Space Station Trace Contaminant Control Assembly," 972267, SAE, 27 ${ }^{\text {th }}$ International Conference on Environmental Systems, Lake Tahoe, Nevada, July 14-17, 1997.

${ }^{4}$ Carter, D. L., Tabb, D., and Perry, J., "Evaluation of an Exploration Water Recovery System Architecture," 2008-01-2140, SAE, $38^{\text {th }}$ International Conference on Environmental Systems, San Francisco, California, 2008.

${ }^{5}$ Ollis, D. F., "Heterogeneous Photocatalytic Oxidation of Atmospheric Trace Contaminants," NASA Research Grant 2-684, North Carolina State University, Raleigh, North Carolina, 1996.

${ }^{6}$ Graf, J. C., Chintawar, P. D., and Kittrell, J. R., "Photocatalytic Purification of Spacecraft Air: Ethylene Destruction," 981803, SAE, $28^{\text {th }}$ International Conference on Environmental Systems, Danvers, Massachusetts, 1998.

${ }^{7}$ Gonzalez-Martin, A., Hennings, B., Ozdemir, K., Drost, J., and Kim, J., "Novel Photocatalytic Filter for Removal of Trace Contaminant Gases," 2006-01-2197, SAE, 36 ${ }^{\text {th }}$ International Conference on Environmental Systems, 2006. 
${ }^{8}$ Gruss, A. F., Casasus, A., and Mazyck, D. W., "VOC Removal by Novel Regenerable Silica-Titania Sorbent and Photocatalytic Technology," 2009-01-2443, SAE, 39 ${ }^{\text {th }}$ International Conference on Environmental Systems, Savannah, Georgia, 2009.

${ }^{9}$ Carter, D. L., Tabb, D., and Perry, J., "Evaluation of an Exploration Water Recovery System Architecture," 2008-01-2140, SAE, $38^{\text {th }}$ International Conference on Environmental Systems, San Francisco, California, June 29-July 2, 2008.

10"UV/PCO Disinfection," Catalyx Technologies URL: http://www.catalyxtech.com/tech.html, [cited June 28, 2010 ].

${ }^{11}$ Ibid.

${ }^{12}$ Ibid.

13،“Compilation of Odor and Taste Threshold Values Data,” F.A. Fazzalari, editor, DS 48A, ATSM, 1978, pp. 60-61.

${ }^{14}$ Hodgson, A. T., Destaillats, H., Hotchi, T., and Fisk, W. J., "Evaluation of a Combined Ultraviolet Photocatalytic Oxidation (UVPCO)/Chemisorbent Air Cleaner for Indoor Air Applications," LBNL-62202, E.O. Lawrence Berkeley National Laboratory, Berkeley, California, 2007, p. 6.

${ }^{15}$ Carter, D. L., Tabb, D., and Perry, J., "Evaluation of an Exploration Water Recovery System Architecture," 2008-01-2140, SAE, $38^{\text {th }}$ International Conference on Environmental Systems, San Francisco, California, 2008, pp. 5-6.

${ }^{16}$ Hay, S. O., Obee, T. N., and Thibaud-Erkey, C., "The Deactivation of Photocatalytic Based Air Purifiers by Ambient Siloxanes." Applied Catalysis B: Environmental 99 (2010) 435-441.

${ }^{17}$ Perry, J. L., "A Design Basis for Spacecraft Cabin Trace Contaminant Control," 2009-01-2592, SAE, $39^{\text {th }}$ International Conference on Environmental Systems, Savannah, Georgia, 2009.

${ }^{18}$ Perry, J. L., "A Review of International Space Station Habitable Element Equipment Offgassing Characteristics," AIAA2010-6068, AIAA, 40 ${ }^{\text {th }}$ International Conference on Environmental Systems, Barcelona, Spain, 2010. 